\section{Is thyroid nodule location associated with malignancy risk?}

\author{
Valeria Ramundo', Livia Lamartina', Rosa Falcone', Laura Ciotti ', Cristiano Lomonaco', \\ Marco Biffoni ${ }^{2}$, Laura Giacomelli ${ }^{2}$, Marianna Maranghi', Cosimo Durante', Giorgio Grani ${ }^{1}$ \\ 'Department of Internal Medicine and Medical Specialties, Sapienza University of Rome, \\ Rome; ${ }^{2}$ Department of Surgical Sciences, Sapienza University of Rome, Rome, Italy
}

Purpose: Nodules located in the upper pole of the thyroid may carry a greater risk for malignancy than those in the lower pole. We conducted a study to analyze the risk of malignancy of nodules depending on location.

Methods: The records of patients undergoing thyroid-nodule fine-needle aspiration cytology (FNAC) at an academic thyroid cancer unit were prospectively collected. The nodules were considered benign in cases of a benign histology or cytology report, and malignant in cases of malignant histology. Pathological findings were analyzed based on the anatomical location of the nodules, which were also scored according to five ultrasonographic classification systems.

Results: Between November 1, 2015 and May 30, 2018, 832 nodules underwent FNAC, of which 557 had a definitive diagnosis. The prevalence of malignancy was not significantly different in the isthmus, right, or left lobe. Among the 227 nodules that had a precise longitudinal location noted (from 219 patients [155 females], aged $56.2 \pm 14.0$ years), malignancy was more frequent in the middle lobe (13.2\%; odds ratio [OR], 9.74; 95\% confidence interval [CI], 1.95 to 48.59). This figure was confirmed in multivariate analyses that took into account nodule composition and the Thyroid Imaging, Reporting, and Data System (TIRADS) classification. Using the American College of Radiologists TIRADS, the upper pole location also demonstrated a slightly significant association with malignancy $(\mathrm{OR}, 6.92 ; 95 \% \mathrm{Cl}, 1.02$ to $46.90 ; \mathrm{P}=0.047)$.

Conclusion: The risk of thyroid malignancy was found to be significantly higher for mid-lobar nodules. This observation was confirmed when suspicious ultrasonographic features were included in a multivariate model, suggesting that the longitudinal location in the lobe may be a risk factor independently of ultrasonographic appearance.

Keywords: Thyroid Imaging, Reporting, and Data System; Thyroid nodule; Cytology; Location; Neoplasms

\section{Introduction}

Thyroid nodules may affect up to $65 \%$ of the general population, and this high rate is mainly due to the increasing detection of nodules through the routine use of ultrasonography in clinical practice [1]. Approximately 16 million individuals in the United States are estimated to have a palpable nodule, and up to 219 million are estimated to have an ultrasound-detectable nodule [2]. Ultrasonography

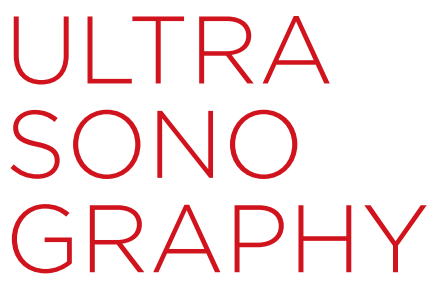

\section{ORIGINAL ARTICLE}

https://doi.org/10.14366/usg. 18050 pISSN: 2288-5919 - elSSN: 2288-5943 Ultrasonography 2019;38:231-235

Received: September 9, 2018 Revised: November 1, 2018 Accepted: November 6, 2018

Correspondence to:

Giorgio Grani, MD, Department of Internal Medicine and Medical Specialties, Sapienza University of Rome, Viale del Policlinico 155, 00161, Rome, Italy

Tel. +39-06-49975130

Fax. +39-06-49975171

E-mail: giorgio.grani@uniroma1.it

*VR, RF, LL, and GG contributed to this paper as recipients of the $\mathrm{PhD}$ program in Biotechnologies and Clinical Medicine at Sapienza University of Rome.

This is an Open Access article distributed under the terms of the Creative Commons Attribution NonCommercial License (http://creativecommons.org/ licenses/by-nc/4.0/) which permits unrestricted noncommercial use, distribution, and reproduction in any medium, provided the original work is properly cited.

Copyright (C) 2019 Korean Society of Ultrasound in Medicine (KSUM)

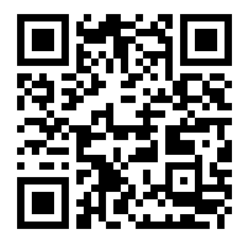

How to cite this article:

Ramundo V, Lamartina L, Falcone R, Ciotti L, Lomonaco $C$, Biffoni $M$, et al. Is thyroid nodule location associated with malignancy risk? Ultrasonography. 2019 Jul;38(3):231-235. 
(US) is the primary tool for the initial cancer risk stratification of thyroid nodules and the subsequent decision of whether to order a fine-needle aspiration biopsy [2-4]. A diagnostic US report should include a description of the background thyroid parenchyma, nodule location, size, US features, and a survey of the cervical lymph nodes $[5,6]$.

Various US characteristics of nodules, such as microcalcifications; hypoechogenicity; irregular, microlobulated, or infiltrative margins; and taller-than-wide shape, are all associated with greater malignancy risk, but no prior study has examined the risk of malignancy in relation to location in the upper versus lower pole of the thyroid, except for a poster presented at the American Association of Clinical Endocrinologists (AACE) 2018 Annual Scientific and Clinical Congress showing that nodules located in the upper pole of the thyroid gland may carry a greater risk for malignancy than those in the lower pole [7]. The aim of this study was to evaluate the frequency of thyroid nodules in various parts of the gland and to correlate the anatomical location with the risk of malignancy.

\section{Materials and Methods}

All records of patients who underwent fine-needle aspiration cytology (FNAC) for thyroid nodules at an academic referral center between November 1, 2015 and May 30, 2018 were prospectively collected. The study was approved by the Institutional Review Board and all patients signed an informed consent form. Neck US was performed by a physician with specific experience and training in thyroid US. The same sonographic equipment (HI VISION Avius, Hitachi Medical Corporation, Inc., Tokyo, Japan) with a highfrequency linear transducer (12-18 MHz) with harmonic imaging was used to image the neck in both transverse and longitudinal views with grayscale and color Doppler imaging. During the realtime US assessment, the site (right or left lobe) and size (transverse, anteroposterior, and longitudinal diameters) of the thyroid nodules subjected to FNAC were recorded.

The US characteristics were evaluated and classified according to five US classification systems: the American College of Radiology (ACR) Thyroid Imaging, Reporting, and Data System (TIRADS) [8,9], the American Association of Clinical Endocrinologists/American College of Endocrinology/Associazione Medici Endocrinologi guidelines [4], the American Thyroid Association guidelines [3], the European Thyroid Association TIRADS [6], and the Korean Society of Thyroid Radiology TIRADS [10]. In each system, a set of US features defines a risk class that represents the likelihood that a nodule is malignant. Given the interobserver variability described for echogenicity [11], other suspicious features [12], and TIRADS classifications $[13,14]$, the evaluation was performed jointly by two examiners (each with 8 years of thyroid imaging experience) after specific training [13].

Nodule cytology was classified according to the Italian Consensus for Thyroid Cytopathology [15]. This scheme is similar to the Bethesda classification system [16]. A composite reference standard was applied. Nodules were considered benign in cases of a benign histology or cytology report, and malignant in cases of malignant histology. Nodules with TR1, TR3A, and TR3B cytology (similar to Bethesda I, III, and IV classes) without a final histologic diagnosis were excluded (Fig. 1).

Using this entire cohort, we studied the prevalence of malignancy according to location (isthmic, right lobe, or left lobe): these 557 nodules constituted the cohort 1 . On that basis, we previously conducted a study to evaluate US features, not location, and those results have already been published [17]. Since the precise location of the lesions was not the main focus of the previous study, the original examiner reported the longitudinal location in the gland (upper, middle, or inferior pole) only for a subset of nodules. Furthermore, nodules involving the whole lobe and isthmic nodules were excluded. In the present study, cytological and pathological findings were then analyzed and correlated with the craniocaudal

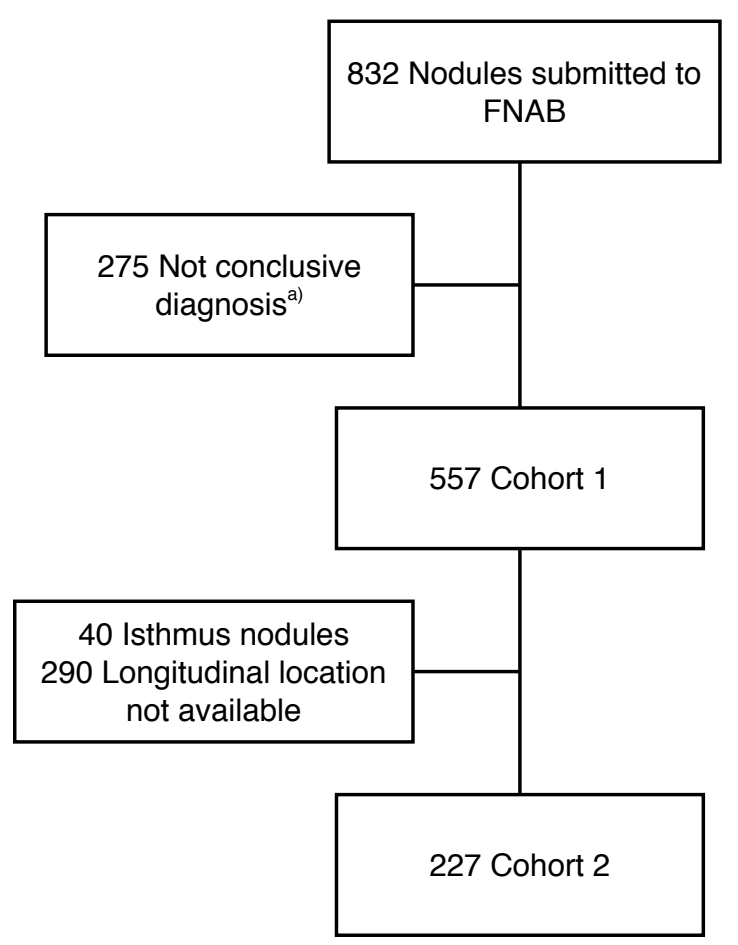

Fig. 1. Flow chart of the study. Cohort 1 corresponds to the one reported in Table 1. Cohort 2 is presented in Tables 2-4. FNAB, fine-needle aspiration biopsy. ${ }^{\text {a) }}$ Nodules with TR1, TR3A, and TR3B cytology (similar to Bethesda I, III and IV classes) without a final histologic diagnosis were excluded. 
Table 4. Multivariate analysis assessing malignancy risk according to thyroid nodule location, adjusting for high-risk estimation according to five ultrasonographic classification systems

\begin{tabular}{|c|c|c|c|c|c|}
\hline Classification & ACR TIRADS & AACE & ATA & EU-TIRADS & K-TIRADS \\
\hline \multicolumn{6}{|l|}{ Upper pole } \\
\hline OR (95\% Cl) & $6.92(1.02-46.90)$ & $5.80(0.91-37.03)$ & $5.88(0.91-38.12)$ & $6.01(0.94-38.59)$ & $4.81(0.75-30.79)$ \\
\hline P-value & 0.047 & 0.063 & 0.063 & 0.059 & 0.097 \\
\hline \multicolumn{6}{|l|}{ Middle lobe } \\
\hline OR $(95 \% \mathrm{Cl})$ & $7.70(1.47-40.38)$ & $10.12(2.00-51.16)$ & $9.26(1.81-47.44)$ & $10.06(1.99-50.86)$ & $7.55(1.45-39.31)$ \\
\hline P-value & 0.016 & 0.005 & 0.008 & 0.005 & 0.016 \\
\hline \multicolumn{6}{|c|}{ High-risk classification } \\
\hline OR $(95 \% \mathrm{Cl})$ & $9.19(2.45-34.52)$ & $3.14(0.92-10.74)$ & $5.54(1.50-20.46)$ & $3.29(0.96-11.31)$ & $7.41(1.95-28.12)$ \\
\hline P-value & 0.001 & 0.068 & 0.01 & 0.059 & 0.003 \\
\hline
\end{tabular}

The multivariate model included longitudinal location and high-risk status in the ultrasonographic classification systems. High-risk classification and solid composition of the nodule were not included in the same model, because composition is one of the items taken into account to classify nodules in some of the classification systems.

ACR, American College of Radiology; TIRADS, Thyroid Imaging, Reporting, and Data System; AACE, American Association of Clinical Endocrinologist; ATA, American Thyroid Association; EU-TIRADS, European TIRADS; K-TIRADS, Korean TIRADS; OR, odds ratio; Cl, confidence interval.

lesions in the inferior pole, with no differences between the two lobes. These data are consistent with the reports of other authors $[19,20]$. The possible causes of this tropism are still unknown and have not been systematically assessed in the literature, except for medullary thyroid cancer (no cases in this study), which is commonly located in the middle-upper portions of the lobes due to the normal aggregation of parafollicular C-cells [21]. However, no similar anatomical explanations are envisioned for papillary and follicular thyroid cancer. It is possible that nodules are in general more frequent in the inferior pole $[19,20,22]$; as a result, the relative frequency of malignant nodules in this area appears to be lower. Interestingly, the location of PTC has also been proposed as a prognostic factor, as lymph node metastasis has been reported to be more common in cases of mid-lobar [23] or upper pole [24] cancers.

This is a brief report reporting preliminary observations, with some limitations. First, the location of thyroid nodules was noted and reported only in a random subset of cases. Furthermore, a composite reference standard was used, with possible false-positive and falsenegative cases. Larger studies, specifically designed to investigate this issue, are needed to better investigate and confirm these data.

In conclusion, the risk of thyroid malignancy was found to be significantly higher for nodules located in the middle lobe. This observation was also confirmed when including solid composition and TIRADS classification as high-risk in a multivariate model, suggesting that a mid-lobe location (or mid-lobe and upper pole location for ACR TIRADS high-risk lesions) may be a risk factor independent of US appearance; therefore, it should be considered for potential inclusion in US classification systems.
ORCID: Valeria Ramundo: https://orcid.org/0000-0003-2709-533X; Livia Lamartina: https://orcid.org/0000-0003-3640-1204; Rosa Falcone: https://orcid.org/00000001-9679-4711; Laura Ciotti: https://orcid.org/0000-0002-9488-530X; Cristiano Lomonaco: https://orcid.org/0000-0002-2413-8122; Marco Biffoni: https://orcid.org/00000002-7905-0881; Laura Giacomelli: https://orcid.org/0000-0003-3598-7522; Marianna Maranghi: https://orcid.org/0000-0002-3117-7488; Cosimo Durante: https://orcid.org/0000-0002-1791-5915; Giorgio Grani: https://orcid.org/0000-00020388-1283

\section{Conflict of Interest}

No potential conflict of interest relevant to this article was reported.

\section{Acknowledgments}

The study was funded by a Research Starter Grant of the University of Rome, Sapienza (to GG, AR216154C9B479B2).

\section{References}

1. Filetti S, Durante C, Torlontano M. Nonsurgical approaches to the management of thyroid nodules. Nat Clin Pract Endocrinol Metab 2006;2:384-394.

2. Durante C, Grani G, Lamartina L, Filetti S, Mandel SJ, Cooper DS. The diagnosis and management of thyroid nodules: a review. JAMA 2018;319:914-924.

3. Haugen BR, Alexander EK, Bible KC, Doherty GM, Mandel SJ, Nikiforov YE, et al. 2015 American Thyroid Association management guidelines for adult patients with thyroid nodules and differentiated thyroid cancer: the American Thyroid Association Guidelines Task Force on Thyroid Nodules and Differentiated Thyroid Cancer. Thyroid 2016;26:1-133.

4. Gharib H, Papini E, Garber JR, Duick DS, Harrell RM, Hegedus L, 
et al. American Association of Clinical Endocrinologists, American College of Endocrinology, and Associazione Medici Endocrinologi medical guidelines for clinical practice for the diagnosis and management of thyroid nodules: 2016 update. Endocr Pract 2016;22:622-639.

5. American Institute of Ultrasound in Medicine; American College of Radiology; Society for Pediatric Radiology; Society of Radiologists in Ultrasound. AIUM practice guideline for the performance of a thyroid and parathyroid ultrasound examination. J Ultrasound Med 2013;32:1319-1329.

6. Russ G, Bonnema SJ, Erdogan MF, Durante C, Ngu R, Leenhardt L. European Thyroid Association guidelines for ultrasound malignancy risk stratification of thyroid nodules in adults: the EU-TIRADS. Eur Thyroid J 2017;6:225-237.

7. Zhang F, Oluwo O, Castillo FB, Gangula, Castillo M, Farag F, et al. Thyroid nodule location on ultrasonography as a predictor of malignancy. Endocr Pract 2019;25:131-137.

8. Grant EG, Tessler FN, Hoang JK, Langer JE, Beland MD, Berland LL, et al. Thyroid ultrasound reporting Lexicon: white paper of the ACR Thyroid Imaging, Reporting and Data System (TIRADS) Committee. J Am Coll Radiol 2015;12(12 Pt A):1272-1279.

9. Tessler FN, Middleton WD, Grant EG, Hoang JK, Berland LL, Teefey SA, et al. ACR Thyroid Imaging, Reporting and Data System (TIRADS): white paper of the ACR TI-RADS Committee. J Am Coll Radiol 2017; 14:587-595.

10. Shin JH, Baek JH, Chung J, Ha EJ, Kim JH, Lee YH, et al. Ultrasonography diagnosis and imaging-based management of thyroid nodules: revised Korean Society of Thyroid Radiology consensus statement and recommendations. Korean J Radiol 2016;17:370-395.

11. Grani G, D'Alessandri M, Carbotta G, Nesca A, Del Sordo $M$, Alessandrini $S$, et al. Grey-scale analysis improves the ultrasonographic evaluation of thyroid nodules. Medicine (Baltimore) 2015;94:e1129.

12. Grani G, Lamartina L, Ascoli V, Bosco D, Nardi F, D'Ambrosio F, et al. Ultrasonography scoring systems can rule out malignancy in cytologically indeterminate thyroid nodules. Endocrine 2017; 57:256-261.

13. Grani G, Lamartina L, Cantisani V, Maranghi M, Lucia P, Durante C. Interobserver agreement of various thyroid imaging reporting and data systems. Endocr Connect 2018;7:1-7.

14. Bae JM, Hahn SY, Shin JH, Ko EY. Inter-exam agreement and diagnostic performance of the Korean thyroid imaging reporting and data system for thyroid nodule assessment: Real-time versus static ultrasonography. Eur J Radiol 2018;98:14-19.

15. Nardi F, Basolo F, Crescenzi A, Fadda G, Frasoldati A, Orlandi F, et al. Italian consensus for the classification and reporting of thyroid cytology. J Endocrinol Invest 2014;37:593-599.

16. Baloch ZW, Cooper DS, Gharib H, Alexander EK. Overview of diagnostic terminology and reporting. In: Ali SZ, Cibas E, eds. The Bethesda System for Reporting Thyroid Cytopathology: definitions, criteria, and explanatory notes. New York: Springer, 2017;1-6.

17. Grani G, Lamartina L, Ascoli V, Bosco D, Biffoni M, Giacomelli L, et al. Reducing the number of unnecessary thyroid biopsies while improving diagnostic accuracy: toward the "right" TIRADS. J Clin Endocrinol Metab 2019;104:95-102.

18. Grani G, Lamartina L, Biffoni M, Giacomelli L, Maranghi M, Falcone $R$, et al. Sonographically estimated risks of malignancy for thyroid nodules computed with five standard classification systems: changes over time and their relation to malignancy. Thyroid 2018;28:1190-1197.

19. Ahmed S, Johnson PT, Horton KM, Lai H, Zaheer A, Tsai S, et al. Prevalence of unsuspected thyroid nodules in adults on contrast enhanced 16- and 64-MDCT of the chest. World J Radiol 2012:4:311-317.

20. Shetty SK, Maher MM, Hahn PF, Halpern EF, Aquino SL. Significance of incidental thyroid lesions detected on CT: correlation among CT, sonography, and pathology. AJR Am J Roentgenol 2006;187:13491356.

21. Schmid KW. Histopathology of C cells and medullary thyroid carcinoma. Recent Results Cancer Res 2015;204:41-60.

22. Sindoni A, Fama F, Rosano A, Scisca C, Dionigi G, Koch CA, et al. Thyroid nodules coexisting with either cystic or solid breast nodules: a new clue for this association between nodules coming from ultrasonography. Gland Surg 2017;6:630-637.

23. Xiang $D$, Xie L, Xu Y, Li Z, Hong Y, Wang P. Papillary thyroid microcarcinomas located at the middle part of the middle third of the thyroid gland correlates with the presence of neck metastasis. Surgery 2015;157:526-533.

24. Zeng RC, Li Q, Lin KL, Zhang W, Gao EL, Huang GL, et al. Predicting the factors of lateral lymph node metastasis in papillary microcarcinoma of the thyroid in eastern China. Clin Transl Oncol 2012;14:842-847. 